\title{
THE IMPORTANCE OF LONG-TERM FOLLOW-UP VISITS FOR KIDNEY DONORS
}

\author{
Makmor $T^{1}$, NurulHuda MS ${ }^{2}$, Raja Noriza RA $^{1}$, Nawi $A^{1}$,Kok Peng $N^{3}$,Soo Kun $L^{3}$, and Muzalwana AT@AM ${ }^{4}$ \\ 1 Department of Administrative Studies and Politics, Faculty of Economics and Administration, University of Malaya, \\ Kuala Lumpur, Malaysia, \\ 2 Department of Economics, Faculty of Economics and Administration, University of Malaya, Kuala Lumpur, Malaysia, \\ 3 Department of Medicine, Faculty of Medicine, University of Malaya, Kuala Lumpur, Malaysia, \\ 4 Department of Applied Statistics, Faculty of Economics and Administration, University of Malaya, Kuala Lumpur, \\ Malaysia
}

\section{Correspondence:}

Makmor Tumin

Associate Professor, Department of Administrative Studies and Politics

Faculty of Economics and Administration, University of Malaya, 50603 Kuala Lumpur, MALAYSIA.

Phone: +603 79673690; Fax: +603 79673719

Email: makmor@um.edu.my

\begin{abstract}
Background: This paper examined the importance and influence of post-transplantation follow-up visits on the quality-of-life (QoL) of living kidney donors in Malaysia.

Methods: Based on data collected from 80 living kidney donors, the relationship between QoL and the frequency of follow-up visits was examined. QoL was measured using standard SF-8 questions to capture its different dimensions.

Results: Donors in the 1991-1998 donation cohort have low QoL, especially in the domains of physical and vitality, compared with the other two cohorts (1999-2005 and 2006-2012). The mean scores showed that donors who never went for any follow-up activities visits experience low QoL in most of the categories, particularly those related to physical activities, implying the importance of follow-up activities visits in influencing the donors' QoL. Lower QoL was recorded for respondents that never received post-transplant treatment.
\end{abstract}

Conclusion: Although this study found no serious post-transplant QoL issues in Malaysia, it is still important to set up a donor registry and provide free and mandatory follow-up visits for all donors in order to adequately monitor their health.

Keywords: kidney donation, living donors, Malaysia, quality of life, sociology

\section{Introduction}

Developments in organ-transplant technology are of less significance if there is a negligible supply of organs. In Malaysia, although 15,489 people were on the waiting list for organ transplantation in July 2012 (1), the deceased donation rate was only 0.64 per million people (2). The short supply of transplant organs from deceased donors necessitates alternative methods of harvesting organs, and living donation seems to be a better option than other possible alternatives. Although living donation is acknowledged as a harmless procedure and donors are generally assumed to be safe physically and mentally posttransplant (3-10), it is worth noting that such a surgical procedure is certainly not risk-free. As of December 2012, there were 1,894 functioning transplanted kidneys in Malaysia, and all were sourced from related donors (11).

Although Malaysia's National Organ, Tissue and Cell Transplantation Policy of 2007, under Article 2.5 (Aim of the Policy) and 2.4 (General Statement of the Policy), stipulated that living donors must attend post-transplantation followup health monitoring visits and that the government would attend to their welfare (12), the implementation of this policy remains almost nonexistent. The first living donation took place in 1975 (12), but only from November 2012 were free medical services provided to living donors (10), and even then services were only provided to Malaysians who donated their organs from November 2012 onwards 
(13). Furthermore, the absence of a living-donor registry makes monitoring difficult.

Studies conducted in both developed $(3,14-18)$ and developing countries (19-21) confirmed that donors enjoy better Quality of Life (QoL) than does the rest of the population. In addition, studies using the SF-36 questionnaire have confirmed that donors not only enjoy better QoL compared with control groups, but also that the majority of donors are willing to donate again, if possible. A systematic review of studies involving 5,139 donors in 19 countries confirmed these norms (7), except in the case of Iran (19). The study in Iran suggested the opposite result, with donors suffering lower QoL on all eight domains of the SF-36 compared to the control group.

However, most of the above studies based their conclusions on small sample sizes, as their authors readily admit. Besides, the method of using only a sample of donors, thus neglecting the rest of the donors, raises the question of whether an inclusive, long-term study of donor QoL might support the same results. For instance, while an earlier study of donors' QoL in Norway indicated that donors enjoy a better QoL than a control group (14), a more recent and robust study in that same country produced the opposite result, in which donors had a lower QoL in the physical and psychological domains (15). Furthermore, another robust study of donors' morbidity found surgical mortality of 3.1 out of 1000 donors. Such studies can only be properly conducted in jurisdictions with a living-donor registry where registration is mandated. The absence of a living-donor registry in many countries, including Malaysia, makes it difficult to trace all donors.

In Malaysia there is evidence that living kidney donors enjoy better QoL than do their healthy counterparts from the general public (20). However, to the best of our knowledge, no study has yet investigated donors' QoL differences based on the time of donation and frequency of follow-up attendance. Hence, this study investigated donors' QoL from these two dimensions.

\section{Subjects and Methods}

A QoL survey was administered to living donors who had donated their kidneys between 1991 and 2012 at the University of Malaya Medical Center (UMMC), Kuala Lumpur, Malaysia. Two enumerators (one from the UMMC and another, independent third party) were instructed to contact all 178 living donors recorded (until June 2012) at the medical center. Of these, they managed to contact 111 donors (or their relatives) currently living in Malaysia via telephone call, which resulted in 80 donors agreeing to participate in the study. Of the 98 non-respondent donors, 67 were unreachable, 11 were too busy, 10 refused to participate, five were abroad, two had follow-ups at other hospitals, two were deceased, and one was chronically ill. We focus on donors who donated before November 2012 in order to reduce bias resulting from the previously mentioned implementation of free medical facilities for organ donors.
SF-8 QoL survey questions were used to make it easier for the respondents to complete questions about other information, such as follow-up activity. The SF- 8 measures eight domains, as follows: (1) physical functioning; (2) role limitations due to physical health; (3) role limitations due to emotional problems; (4) energy/fatigue; (5) emotional well-being; (6) social functioning; (7) pain; and (8) general health. We prepared the questionnaire in three different languages (Malay, English, and Mandarin).

First, we analyzed donors' overall QoL based on the eight QoL domains, comparing them with a gender- and agematched, healthy control group (individuals identified as having systolic blood pressure of $140 \mathrm{mmHg}$ and diastolic blood pressure below $90 \mathrm{mmHg}$ at the time of survey, no history of medical problems, and not being treated with drugs for hypertension) with income higher than RM 3,000 (700 USD).

In this paper, we only compare donors' QoL by different cohorts of time since donation, followed by comparing their QoL based on their frequencies of follow-up attendance. Discussion of the comparison between the donor and control group has been published elsewhere (20). We converted the scores for each QoL category from a Likert-type scale to percentages, such that the higher the percentage, the lower the QoL. Based on a tabulation of the donors, we divided the donors into three donation cohorts: (1) 1991-1998; (2) 1999-2005; and (3) 2006-2012.

This study received ethics approval from the Medical Ethics Committee of UMMC on 19th July 2012 (MEC Ref. No: 932.23).

\section{Results}

The overall results for donors' QoL are shown in Figure 1 , along with the QoL domains and mean scores for all donors. On average, donors scored vitality and general health the highest, indicating that donors' QoL was the lowest in these categories.

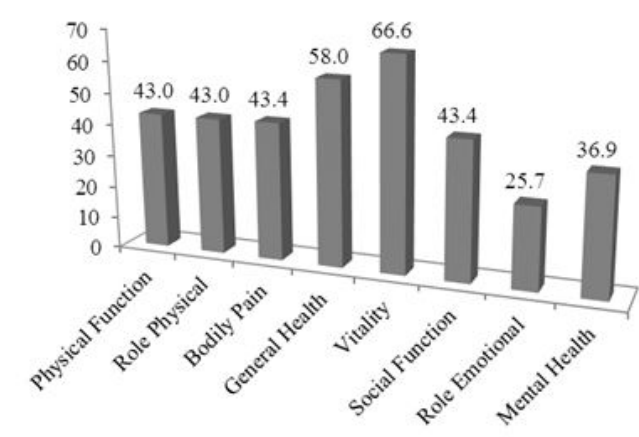

Figure 1: Respondents' overall QoL.

Basic background information on the 80 respondent donors follows. Women outnumbered men (51/80), and 
Chinese outnumbered other ethnicities (50/80; Malay=16 and Indian=14). A total of 64 participants were married, while 13 were single and three were widowed/divorced. Regarding education, 46 had finished at least a secondary level of education, 26 had finished primary level, and eight have had tertiary-level education.

Table 1: Respondents' background information at the time of donation and at the time of survey administration.

\begin{tabular}{lllll}
\hline Variable & \multicolumn{2}{l}{$\begin{array}{l}\text { At the time of } \\
\text { donation }\end{array}$} & \multicolumn{2}{l}{$\begin{array}{l}\text { At the time of } \\
\text { survey }\end{array}$} \\
\hline Age & No. & $\%$ & No. & $\%$ \\
40 and below & 31 & $(38.8 \%)$ & 15 & $(18.8 \%)$ \\
41 to 55 & 33 & $(41.2 \%)$ & 32 & $(40.0 \%)$ \\
56 and above & 16 & $(20.0 \%)$ & 33 & $(41.2 \%)$ \\
\hline $\begin{array}{l}\text { Employment status } \\
\text { Homemaker }\end{array}$ & 21 & $(26.3 \%)$ & 16 & $(20.0 \%)$ \\
$\begin{array}{l}\text { Unemployed } \\
\text { Self-employed }\end{array}$ & 15 & $(18.8 \%)$ & 10 & $(12.5 \%)$ \\
$\begin{array}{l}\text { Public-sector } \\
\text { employee }\end{array}$ & 9 & $(17.5 \%)$ & 16 & $(20.0 \%)$ \\
$\begin{array}{l}\text { Private-sector } \\
\text { employee }\end{array}$ & 15 & $(18.8 \%)$ & 19 & $(23.8 \%)$ \\
Other & 6 & $(7.5 \%)$ & 7 & $(8.8 \%)$ \\
\hline
\end{tabular}

\begin{tabular}{lcccc}
\hline $\begin{array}{l}\text { Donor's monthly } \\
\text { income }\end{array}$ & & & & \\
$\begin{array}{l}\text { None } \\
\begin{array}{l}\text { Less than RM3000 } \\
\text { (700 USD) }\end{array}\end{array}$ & 36 & $(45.0 \%)$ & 25 & $(31.3 \%)$ \\
$\begin{array}{l}\text { RM3000 (700 USD) } \\
\text { and above }\end{array}$ & 5 & $(68.8 \%)$ & 43 & $(53.8 \%)$ \\
\hline
\end{tabular}

\begin{tabular}{|c|c|c|c|c|}
\hline \multicolumn{5}{|l|}{$\begin{array}{l}\text { No-income: donor's } \\
\text { supporter }^{1}\end{array}$} \\
\hline $\begin{array}{l}\text { Supported mainly } \\
\text { by the family }\end{array}$ & 23 & (71.9\%) & 19 & (79.2\%) \\
\hline $\begin{array}{l}\text { Supported mainly } \\
\text { by the recipient }\end{array}$ & 1 & $(3.1 \%)$ & 0 & $(0.0 \%)$ \\
\hline $\begin{array}{l}\text { Supported mainly } \\
\text { by own savings }\end{array}$ & 5 & (15.6\%) & 3 & $(12.5 \%)$ \\
\hline Other & 3 & (9.4\%) & 2 & (8.3\%) \\
\hline
\end{tabular}

The information in Table 1 clearly indicates that a large portion of respondents have low incomes. The number of donors without income nonetheless decreased between the time of donation and the administration of the survey, even though many donors had reached the age of 40 and above by the time the survey was administered. Donors without income were not only supported by their families, but also by other means such as through the support of the organ recipient, own savings and others.

Next, based on the time since donation, we divided the donors into three categories: (1) 1991-1998; (2) 19992005; and (3) 2006-2012. The mean age for each cohort was $56.8,54.8$, and 47.9 , respectively. Table 2 clearly illustrates that those in the first cohort suffered low QoL. Their mean scores, as shown in Table 2, depict that donors who underwent transplantation between 1991 and 1998 experienced the worst QoL in all categories except role emotional and mental health (Figure 2).

Table 2: Respondents' QoL by domain, based on time-sincedonation cohort (\%).

\begin{tabular}{lccc}
\hline Domain & $1991-1998$ & $\begin{array}{c}1999- \\
2005\end{array}$ & $\begin{array}{c}2006- \\
2012\end{array}$ \\
\hline Physical function & 45.6 & 45.5 & 41.5 \\
Role physical & 45.6 & 45.5 & 41.5 \\
Bodily pain & 40 & 40 & 38 \\
General health & 58.9 & 55.5 & 57 \\
Vitality & & & 57 \\
Social function & 41.1 & 55.5 & 35 \\
Role emotional & 23.3 & 30.9 & 23.4 \\
Mental health & 34.9 & 38.3 & 36.9 \\
\hline
\end{tabular}

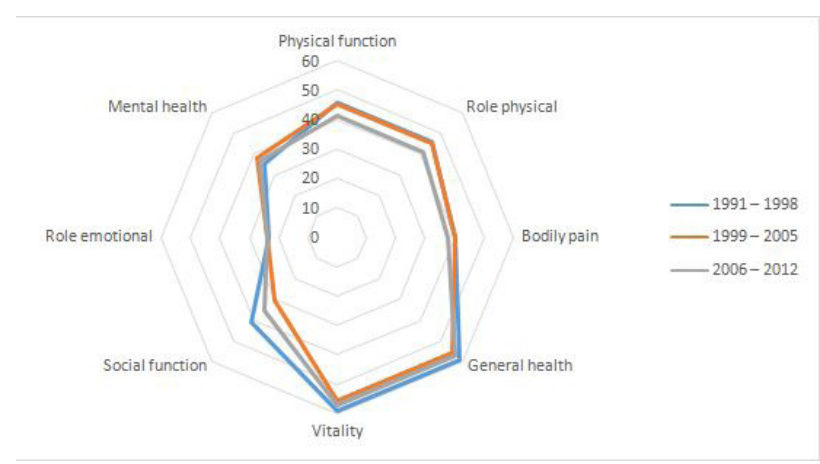

Figure 2: Donors' QoL based on time since donation. The figure compares QoL of the donors by donation cohorts. The closer the lines are to the center of the radar chart, the better is those donors' QoL. In general, the line for donors from the 2009-2012 cohort always lies inside the lines representing the other two cohorts. Donors from 1991-1998 scored lowest on the social, vitality, and general health dimensions. 
Donors' QoL was also assessed based on their follow-up visit frequencies. Donors' follow-up activities in terms of percentages were as follows: $31.25 \%$ of respondents had regular follow-up visits ( $n=25) ; 62.5 \%(n=50)$ had one visit in several years; and only $6.25 \%(n=5)$ had never had any follow-up visits. The mean scores for each of the QoL categories are presented in Table 3 and suggest a significant difference in three of the QoL categories: (1) physical function; (2) role physical; and (3) vitality.

The mean scores show that donors who never went for any follow-up visits experience low QoL in most categories, particularly those related to physical activities, implying the importance of follow-up visits in influencing donors' QoL (Figure 3).

Table 3: Respondents' QoL by domain, based on frequency of follow-up attendance (\%)

\begin{tabular}{lccc}
\hline Quality of Life & Regular & $\begin{array}{c}\text { Non- } \\
\text { regular }\end{array}$ & Never \\
\hline Physical function & 40.7 & 44.4 & 72 \\
Role physical & 40.7 & 44.4 & 72 \\
Bodily pain & 37.5 & 43.3 & 40 \\
General health & 58.2 & 56.7 & 44 \\
Vitality & 67.4 & 61.1 & 76 \\
Social function & 34.4 & 41.1 & 20 \\
Role emotional & 22.2 & 26.8 & 26.4 \\
Mental health & 37.3 & 33.9 & 41.6 \\
\hline
\end{tabular}

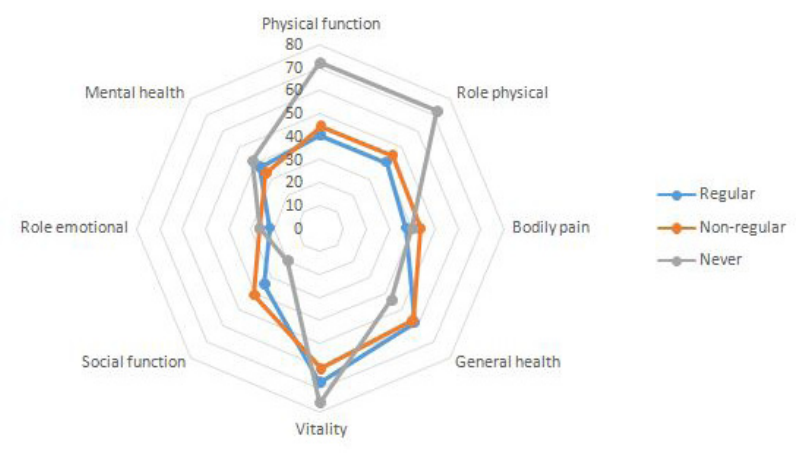

Figure 3: Donors' QoL based on follow-up frequencies. The figure compares QoL of the donors by frequency of follow-up visits. The closer the lines are to the center, the better is those donors' QoL. Donors who committed to regular visits scored better, on average, as compared to non-regular and non-visitor groups, except in terms of general health. Those who never attended any follow-up visits experienced poor QoL, especially on the physical and role physical dimensions.

\section{Discussion}

Most relevant literature provides evidence that kidney donors' QoL is not lower than their counterparts from the general public or from healthy individuals who would be eligible for kidney donation (3-10). A recent and large study in Norway introduced the surprising suggestion that in the long run, approximately 10 years after kidney donation, all-cause mortality increases among living kidney donors compared to healthy eligible-donor controls (24). The results of our time-grouped study of kidney donors are in line with this finding, revealing that the older the donor, the lower the QoL, with particularly lower general heath, vitality, and social function (Figure 2 ).

There is evidence that long-term follow-up appointments lower donors' morbidity risk (25). The findings of this study add to this evidence. Thus, serious calls have been made by donors and policymakers regarding the importance of follow-up visits post-transplantation (26). In fact, some developed countries have established special donor clinics to cater to the physical and psychological needs of donors and also to provide consultation services for them. The above findings urge Malaysia towards serious efforts to establish a national donor registry with mandated followup attendance, since this is the only method to ensure that the health of living donors is monitored. The government should provide all living donors with free medical services (at all levels, including secondary and tertiary), regardless of their date of donation, in order to guarantee that living donors-who are the majority of donors-attend their follow-up visits. The literature reveals that eligible donors may not donate due to their fear of facing financial problems after donation (27-28), so we expect that providing free follow-up care would tend to increase the number of living donations.

\section{Conclusion}

This study revealed two important findings. Firstly, living kidney donors' QoL was found to decline over the long run. Secondly, living donors with higher commitments to post-donation follow-up visits enjoy better QoL than those who never or infrequently attend follow-ups. Hence, this study suggests that officials should take the initiative to establish a living-donor registry and to make follow-up attendance mandatory and free of charge for all donors. These changes would enhance donors' QoL.

\section{Acknowledgement}

The authors wish to thank the University of Malaya for funding the research under the University of Malaya Research Grant Scheme (Grant Number: RG283/11HTM). 


\section{References}

1. National Transplant Resource Centre, Ministry of Health Malaysia. http://www.agiftoflife.gov.my/ statistics2.html. Accessed July 17, 2012.

2. International registry of organ donation and transplantation (IRODaT). http://www.irodat.org/. Accessed on 28 October 2014.

3. Mjøen G, Stavem K, Westlie L, et al. Quality of life in kidney donors. Am J Transplant. 2001;11(6):1315-19.

4. Johnson EM, Anderson JK, Jacobs C et al. Long-term follow-up of living kidney donors: Quality of life after donation. Transplantation. 1999; 67:717-21.

5. Ibrahim HN, Foley R, Tan LP, et al. Long-term consequences of kidney donation. $N$ Engl J Med. 2009; (360):459-69.

6. Segev DL, Muzaale AD, Caffo BS, et al. Perioperative mortality and long-term survival following live kidney donation. JAMA. 2010; 303(10):959-66.

7. Clemens KK, Thiessen-Philbrook H, Parikh CR, et al. Psychosocial health of living kidney donors: A systematic review. Am J Transplant. 2006; 6(12):2965-77.

8. Okamoto M, Akioka K, Nobori S. Short- and longterm outcomes after kidney donation: Analysis of 601 cases over a 35-year period at Japanese single center. Transplantation 2009; 87:419-23.

9. Mjoen G, Reisaeter A, Hallan S, et al. Overall and cardiovascular mortality in Norwegian kidney donors compared to the background population. Nephrol Dial Transplant 2012; 27:443-47.

10. Mjoen G, Midtvendt K, Holme I, et al. One- and fiveyear follow-ups on blood pressure and renal function in kidney donors. Transplant Int. 2010; 24(1):73-77.

11. Lim YN, Ong LM, Goh BL (eds). 20th report of the Malaysian dialysis and transplant registry. Kuala Lumpur: National Renal Registry, Malaysian Society of Nephrology, 2012.

12. Ministry of Health Malaysia. National organ, tissue, and cell transplantation policy. Kuala Lumpur: Ministry of Health Malaysia, 2007.

13. Ministry of Health Malaysia. Circular (64) dlm. KKM58/900/69 Jld. 7 dated November 21, 2012.

14. Clemens K, Boudville N, Dew MA, et al. The long-term quality of life of living kidney donors: A multicenter cohort study. Am J Transplant. 2001; 11(3):463-69.
15. Johnson EM, Anderson JK, Jacobs C, et al. Long-term follow-up of living kidney donors: Quality of life after donation. Transplantation 1999; 67:717-21.

16. Shrestha A, Vallance C, McKane WS, Shrestha BM, Raftery AT. Quality of life of living kidney donors: A single-center experience. Transpl P 2008; 40:375-77.

17. Feltrin A, Pegoraro R, Rago C, et al. Experience of donation and quality of life in living kidney and liver donors. Transplant Int. 2008; 21(5):466-72.

18. Frade IC, Foncesca I, Dias L, et al. Impact assessment in living kidney donation: Psychosocial aspects in the donor. Transpl P 2008; 40:677-81.

19. Zhao WY, Zeng L, Zhu, YH. Psychosocial evaluation of Chinese living related kidney donors. Clin Transplant. 2010; 24(6):766-71.

20. Tumin M, Abdul TAMM, Mohd SN, et al. A comparison of donor and control group quality of life. Ann Transplant. 2014; (19):112-18.

21. Taskintuna N, Ozcurumez G, Duru C, Colak T, Haberal M. Psychosocial aspects of living-related donor renal transplantation: Quality of life and mood in recipients, donors and controls. Int J Psychiat Clin. 2009; 13(3):218-22.

22. Lima DX, Petroianu A, Hauter HL. Quality of life and surgical complications of kidney donors in the late post-operative period in Brazil. Nephrol Dial Transpl. 2006; 21(11):3238-42.

23. Zargooshi J. Quality of life of Iranian kidney "donors". The J Urol. 2001; 166 (5):1790-99.

24. Mjoen G, Hallan S, Hartmann A, et al. Long-term risks for kidney donors. Kidney Int. 2013; 86:162167.

25. Boudville N, et al. Meta-analysis: Risk for hypertension in living kidney donors. Ann Intern Med 2006;145:8596.

26. Leichtman A, et al. Living kidney donor followup: State-of-the-art and future directions. Am J Transplant. 2011; 11(12):2561-68.

27. Klarenbach S, Garg AX, Vlaicu S. Living organ donors face financial barriers: A national reimbursement policy is needed. Can Med Am J 2006; 174:797-98.

28. Knotts RS, Finn WF, Armstrong T. Psychosocial factors impacting patients, donors, and nondonors involved in renal transplant evaluation. Perspect 1996; 15:1123. 
